\title{
CO-EXISTING FIBROUS DYSPLASIA AND MENINGOTHELIAL MENINGIOMA
}

\author{
Raphael Vicente Alves ${ }^{7}$, Anderson Rodrigo Souza ${ }^{7}$, Alessandra dos Santos Silva ${ }^{2}$, \\ Vera Lúcia Nocchi Cardim², Roberto Godoy?
}

Co-existing fibrous dysplasia and meningothelial meningioma is extremely rare'. A search at "PubMed" (U.S. National Library of Medicine) with terms "fibrous", "dysplasia" and "meningioma" demonstrated a total of 7 cases reported. Three cases in association with McCune-Albright syndrome ${ }^{2,3}$, two cases in the Chinese literature ${ }^{4}$, one case with multiple globoid meningiomas with craniomandibular fibrous dysplasia ${ }^{5}$, and one reported case of atypical lymphoplasmacyte-rich meningioma'.

To the best of our knowledge, this is the first reported case of co-existing fibrous dysplasia and meningothelial meningioma with histopathological diagnosis ${ }^{1,6,7}$.

\section{CASE}

A 35-year-old man was admitted to Plastic Surgery unit with a 5 years history of hard, painless growing mass in the right frontal basal region. He denied visual alteration. No personal or familiar history of brain diseases. Clinical examination showed only a protrusion of his right forehead and proptosis. Visual acuity/ field and extra ocular muscles were normal. Fundoscopy revealed no alteration at optic nerve. Higher mental functions were preserved. There were no other deficits. A computed tomography without contrast revealed a supraorbital hyperostotic lesion.
The clinical presentation and neuroimaging appearance led to an initial diagnosis of fibrous dysplasia in the frontal bone (Fig 1).

A bi-coronal approach was done with right frontal/supra-orbital craniotomy and a total excision of the frontal bone lesion. Intra-operatively was observed an atypical aspect of dura matter next to the bone lesion. The neurosurgery unit was called to explore the dura matter. After opening dura matter, it was performed microneurosurgery techniques to a lesion attached to the dura and displacing the adjacent arachnoid and brain. Complete dissection of the lesion by the "arachnoid plane" was done. The operation findings suggest being a meningioma with bone hyperostosis. Bone, dura matter and extra-axial lesion were sent for histopatological examination.

Histopathological examination features a diagnosis of a "fibrous dysplasia" (Fig 2A) and "meningothelial meningioma" (Fig 2B).

No complication was observed during the postoperative period. The patient was discharged 1 week after surgery with small asymmetry of forehead. Magnetic resonance imaging (MRI) one month after surgery showed complete resection of the meningioma.

\section{DISCUSSION}

Fibrous dysplasia is a congenital, non-familial, benign
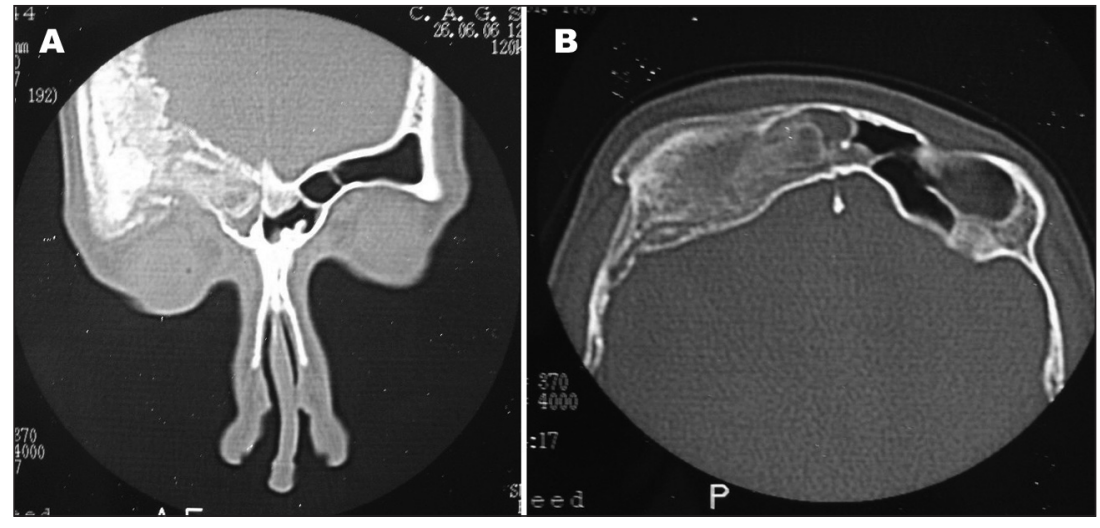

Fig 1. [A] Coronal reconstruction computed tomography scan showing a supraorbital hyperostotic bone lesion resulting in proptosis. [B] Bone window reveal an intradiploic lesion with extension to the frontal sinus Axial computed tomography scan, bone window, demonstrating the frontal bone lesion.

\section{COEXISTÊNCIA DE DISPLASIA FIBROSA E MENINGIOMA MENINGOEPITELIAL}

Neurosurgery Unit and Plastic Surgery Unit, Hospital São Joaquim, Real e Benemérita Beneficência Portuguesa de São Paulo, São Paulo SP, Brazil: 'Neurosurgeon; ${ }^{2}$ Plastic Surgeon.

Received 4 February 2009, received in final form 4 May 2009. Accepted 11 May 2009.

Dr. Raphael Vicente Alves - Rua Estado de Israel 907 / 31 - 04022-002 São Paulo SP - Brasil. E-mail: raphaelvalves@yahoo.com.br 

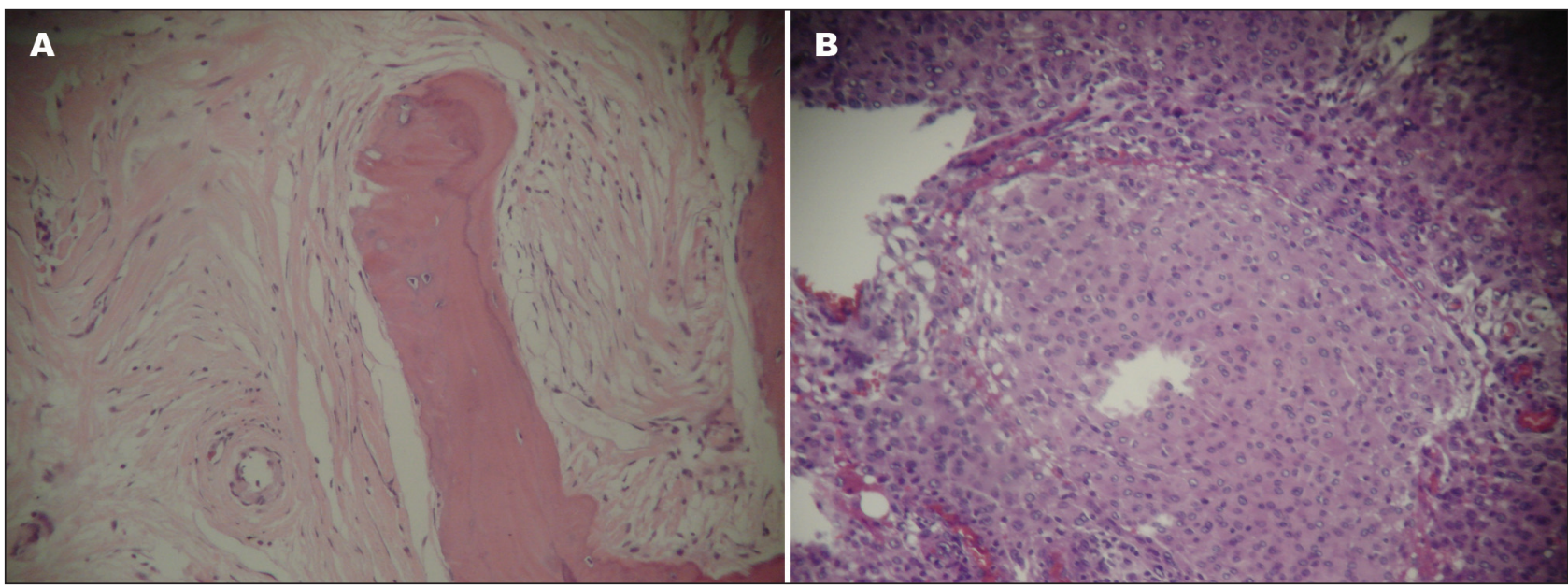

Fig 2. [A] Paraffin section with fibrous dysplasia at bone tissue (HE staining X 100); [B] meningothelial meningioma at frontal lesion.

anomaly of bone development occurring in single or several bones, characterized by the replacement of normal bone by fibro-osseous tissue.? It represents $2.5 \%$ of all osseous neoplasias and is more frequently in women (2:1)'. Approximately $70-80 \%$ of cases are monostotic and $20-$ $30 \%$ are polyostotic. Monostotic form involves the skull and facial bones in $10-25 \%$ and polyostotic in $50 \%$ cases. Fibrous dysplasia can be present as one of the components of McCune-Albright syndrome ${ }^{1,2,3,7}$.

Approximately one-third of patients with dysplasia fibrous has involvement of cranial and face bones. These patients commonly present with headaches, facial pain, cranial nerve palsy and facial deformities due to bone compression ${ }^{1,7}$.

Meningiomas can to present in association with other tumors but it is considered coincidence, except by occurs with breast cancer that is significant ${ }^{8}$. About $8 \%$ of meningioma patients experience multiple tumors (excluding patients with neurofibromatosis) ${ }^{9}$. Patients with neurofibromatosis however may develop gliomas and vestibular schwannomas in association with meningiomas ${ }^{8,10}$.

Meningothelial meningioma is a WHO Grade I and there is no prognostic difference between this morphological variant and those that exhibit "classic" pattern (meningothelial, fibrous, transitional, psmmomatous, angiomatous, microcystic, secretory, lymphoplasmacyte rich and metaplastic) ${ }^{8}$.

There is no exact etiopathological factor known for the coexistence of these tumors. However, there seems to be a common but undetected influencing factor between the two tumors ${ }^{1,5,7}$. The co-existing of tumors in central nervous system should be reported to help us understand the etiology of these lesions.

In summary, We report in this paper a patient 35-yearold man with extremely rare case of coexisting fibrous dysplasia and meningothelial meningioma. The occurrence of meningioma and fibrous dysplasia is infrequently reported and a coexisting fibrous dysplasia and meningothelial meningioma with histopathological diagnosis has not previously been reported in the literature ${ }^{1,6,7}$.

\section{REFERENCES}

1. Ghosal N, Furtado SV, Santosh V, Sridhar M, Hedge AS. Co-existing fibrous dysplasia and atypical lymphoplasmacyte-rich meningioma. Neuropathology 2007;27:269-272.

2. Bayas A, Naumann M, Wever S, Toyka KV. Meningioma associated with McCune-Albright syndrome. J Neurol 1999;246:199-200.

3. Fehlow P, Walther F, Assmann H. [McCune-Albright syndrome in association with meningioma and mental and psychological retardation]. Klin Padiatr 1992;204:447-452. [German]

4. Gao H, Zhang JL, Qi ST. [Fibrous dysplasia of the skull complicated with meningioma: report of 2 cases]. Jun Yi Da Xue Bao 2002;22:664. [Chinese]

5. Tasar M, Ors F, Yetiser S, Ugurei MS, Uçoz T. Multiple globoid meningiomas associated with craniomandibular fibrous dysplasia: case report. Clin Imaging 2004;28:20-22.

6. Boon AP, Carey MP, Hockley A. Meningioma mimicking fibrous dysplasia of the skull. J Neurol Neurosurg Psychiatry 1990;53:818.

7. Frankel J, Ianotti F, Powell M, Schon F. Meningioma: an unrecognized complication of fibrous dysplasia of skull? J Neurol Neurosurg Psychiatry 1989;52:546-547.

8. Al-Mefty O, Heth J. Meningiomas. In: Rengachary SS, Ellenbogen (Eds): Principles of neurosurgery. Ed 2. England: Elsevier, 2005:486-500.

9. Simon M, Bostrom JP, Hartmann C. Molecular genetics of meningiomas: from basic research to potential clinical applications. Neurosurgery 2007;60:787-798.

10. Martuza RL. Neurofibromatosis as a model for tumor formation in the human nervous system. In: Salcman (Ed). Neurobiology of brain tumors: concepts in neurosurgery. Baltimore: Williams \& Wilkins, 1991;4:53-62. 